\title{
FRONTEIRAS DO CAPITAL ENTRE BRASIL E PARAGUAI
}

\author{
Roberto Navega ${ }^{1}$ \\ Tatiane dos Santos Navega Costa ${ }^{2}$
}

\begin{abstract}
RESUMO: O presente artigo tem como objetivo trazer dados a respeito da íntima relação que vem se estabelecendo entre Brasil e Paraguai referente à tentativa de atração de investimentos feita por este último, na obtenção de capitais provenientes do primeiro. Iremos demonstrar as estratégias adotadas pelo governo paraguaio e como os empresários brasileiros estão se aproveitando de tal fato. Utilizaremos, a seguir, como metodologia, uma investigação bibliográfica feita em um manual de divulgação de 2015 da FIEMS, Federação das Indústrias do Mato Grosso do Sul, referente às possibilidades de investimento de capitais brasileiros em solo paraguaio. Tal manual se chama Guia de Investimento Paraguai, e traz uma série de dados, dicas, explicações, procedimentos, para facilitar a vida do investidor. Esperamos ao final do texto termos explicitado as estratégias do Paraguai para atrair investimentos, como também as estratégias dos empresários brasileiros para aproveitar tais oportunidades de negócio. Procuraremos avaliar os possíveis motivos da adoção destas práticas por parte do Paraguai e os possíveis efeitos de tais práticas a longo prazo, tentando ampliar nossa visão em relação aos movimentos, fluxos e estratégias na fronteira dos dois países.
\end{abstract}

Palavras chave: Investimento; Brasil; Paraguai; Fronteira; Capital.

\section{CAPITAL BORDERS BETWEEN BRAZIL AND PARAGUAY}

RESUMEN: Este artículo tiene como objetivo traer datos sobre la estrecha relación que se ha establecido entre Brasil y Paraguay con respecto al intento de atraer inversiones realizadas por este último, para obtener capital del primero. Vamos a demostrar las estrategias adoptadas por el gobierno paraguayo y cómo los empresarios brasileños se están aprovechando de este hecho. A continuación, utilizaremos como metodologia, una investigación bibliográfica realizada en un manual de divulgación 2015 de FIEMS, Federación de Industrias de Mato Grosso do Sul, en referencia a las posibilidades de inversión de capital brasileño en suelo paraguayo. Este manual se llama Paraguay Investment Guide y ofrece una serie de datos, consellos, explicaciones y procedimientos para facilitar la vida del inversor. Esperamos al final del texto que hayamos explicado las estrategias de Paraguay para atraer inversiones, así como las estrategias de los empresarios brasileños para aprovechar esas oportunidades comerciales. Intentaremos evaluar las posibles razones de la adopción de estas prácticas por parte de Paraguay y

\footnotetext{
${ }^{1}$ Bacharel em Filosofia; Mestrando no Programa de Pós-Graduação em Sociedade, Cultura e Fronteiras, Unioeste, Foz do Iguaçu. Vinculo institucional: PPG em Sociedade, Cultura e Fronteiras, Unioeste, Foz do Iguaçu. E-mail: ramosnavega@gmail.com

${ }^{2}$ Pedagoga, Psicóloga, Psicopedagoga, Neuropsicóloga. vinculo institucional: Coordenadora do curso de Pedagogia e Docente na Uniamérica, Foz do Iguaçu. E-mail: navegapsicologia@gmail.com

Programas de Pós-Graduação em Ciências Sociais e Filosofia - UNIOESTE - Rua da Faculdade 645. Toledo - PR. CEP 85.903-000 Email: revistaalamedas@gmail.com
} 
los posibles efectos a largo plazo de tales prácticas, tratando de ampliar nuestra visión de los movimientos, flujos y estrategias fronterizas.

Palabras-clave: Inversión; Brasil; Paraguay; Frontera; Capital.

\section{INTRODUÇÃO}

O Paraguai vem apresentando um crescimento do seu PIB ano após ano, apesar do fraco desempenho de Brasil (1,1\% em 2018) ${ }^{3}$ e Argentina (-2,5\% em 2018) ${ }^{4}$, seus maiores parceiros comerciais do Mercosul, o que pode sugerir que sua estratégia de gerir a economia tem tido um bom resultado. Ao mesmo tempo, há uma série de fatos que precisam ser conhecidos para termos uma noção de quais são estas medidas de cunho econômico e quais podem ser seus impactos.

Ao fazermos uma pesquisa bibliográfica a respeito da economia paraguaia nos deparamos com um conjunto de documentos produzidos tanto pelo governo paraguaio, quanto por federações de empresários no Brasil, o que nos chamou a atenção para procurarmos entender do que se tratava de quais maneiras estes sujeitos privilegiados poderiam se beneficiar com tais medidas, e como cada um se via neste campo.

Assim, buscamos apresentar o chamado Guia de Investimento Paraguai como um modelo de publicidade difundida entre os empresários, tendo como objetivo levar capitais para o outro lado da fronteira, com a promessa de que eles voltem maiores do que foram. Mostraremos como este manual provém não do Brasil, mas do próprio Paraguai, e que o mútuo interesse tem movido tais capitais buscando a aumentar o lucro, por um lado, e o crescimento da produção, por outro.

Desta forma pretendemos: 1) apresentar a estratégia do governo paraguaio para atrair investimentos brasileiros; 2) demonstrar como os empresários nacionais tentam aproveitar tais oportunidades para aumentarem seus ganhos de capital; 3) discutir os possíveis impactos futuros de tais práticas a médio e longo prazo. Ao final do texto

\footnotetext{
${ }^{3}$ http://agenciabrasil.ebc.com.br/economia/noticia/2019-02/pib-fecha-2018-com-crescimento-de-11mostra-ibge.

${ }^{4}$ https://valor.globo.com/mundo/noticia/2019/03/21/argentina-registra-queda-de-25-no-pib-em2018.ghtml.
} 
esperamos apresentar ao leitor um cenário bem amplo dos pontos elencados acima e esperamos enriquecer a discussão a respeito de tais práticas.

Para realizarmos atarefa a que nos propomos a seguir utilizaremos um texto base, e dele procuraremos dados para embasar as declarações do texto - sempre que possível. Ora o texto apresentará dados estatísticos, ora dados de legislação, ora dados qualitativos, e o leitor verá um discurso de tentativa de convencimento, a tentativa de venda de uma ideia, a saber, a de se investir no Paraguai para conseguir mais lucros através de benefícios fiscais.

O presente trabalho se divide em uma apresentação do texto base, produzido pela FIEMS, indo aos pontos mais importantes, procurando entender a lógica da propaganda. A seguir, discutiremos nossas impressões de tal técnica de marketing e quais os possíveis efeitos às economias e sociedades dos dois lados da fronteira.

\section{GUIA DE INVESTIMENTOS PARAGUAI}

O guia comercial em questão tem setenta e três páginas, e nelas apresenta um panorama geral de dados, dicas, legislação, onde ir, como proceder, quais os cuidados necessários, documentação apropriada, moeda a ser usada. Em suma, um verdadeiro manual do investidor brasileiro que esteja interessado em aumentar seus lucros, e que vê nas condições econômicas do Brasil um empecilho a tal aumento.

Produzido no ano de 2015 o guia é muito prático, direto ao assunto, apresenta apenas o indispensável para se poder convencer o leitor a abrir um negócio no país vizinho. E o mais curioso é que encontramos mais um manual praticamente idêntico a este, só que em espanhol, produzido pela Cámara de Comercio Paraguay Brasil, chamado "Guia de Inversiones 2018-2019”, só que discretamente postado num obscuro site da internet, especializado em upload e download de materiais, como livros e revistas, só que com a função download desabilitada, sendo necessário a leitura de tal manual apenas no leitor do site, que é muito incômodo e pesado, dificultando em demasia sua utilização.

Tal prática demonstra o amadorismo da tentativa de divulgação de tal entidade empresarial, já que desta forma não conseguirão atingir o público alvo, os empresários 
brasileiros, e o fato de estar em espanhol aumenta o grau de dificuldades apresentadas. Ao mesmo tempo, quando a FIEMS traz um texto em português, garante o acesso do público via download de um arquivo PDF, de fácil leitura e manuseio, apresenta uma maior organização e foco nos resultados esperados.

O texto do guia começa de uma forma bem simples, apresentando a localização do Paraguai na América do Sul (p. 4), mostrando um mapa onde podemos ver o continente, com o Paraguai ao centro, e marcados com setas coloridas os caminhos de escoamento da produção para portos próximos, com destaque de fluxos partindo de Campo Grande-MS, passando por Ponta-Porã, indo para Concepción (e de lá para o Chile), e para Asunción (e de lá para a Argentina e o Uruguai). Curiosamente não há fluxo apontando para o escoamento pela fronteira entre Ciudad del Este e Foz do Iguaçu, nem de Salto del Guairá para Guaíra, e de lá para Paranaguá.

O texto nesta página é bem direto, pois informa que o Paraguai está numa posição privilegiada, no centro do continente, com terras cultiváveis e com um parque industrial ainda pequeno, proporcionando chances de investir ou de exportar para eles: "aproximidade geográfica, o reduzido parque industrial paraguaio e o volume proporcionalmente elevado de importações do país favorecem as exportações brasileiras." (CIN-MS-FIEMS, p. 4)

A seguir, o estudo apresenta o fato de haver mais de quinhentos mil cidadãos brasileiros vivendo legalmente no Paraguai como um dado positivo para o empresário, e define a justificativa do texto como proveniente das "vantagens comerciais e de negócios proporcionadas pelo Paraguai ao empresariado brasileiro.” (CIN-MS-FIEMS, p. 5)

Logo abaixo é exposta a fonte dos dados em que o texto se baseia, a saber, "Estudo Mercadológico com foco no Paraguai; Como Exportar para o Paraguai;Embaixada do Paraguai no Brasil.” (Iden) Atentem para a presença da embaixada paraguaia no Brasil como fonte, o que pode ser um indício da afinidade das políticas do governo vizinho com as práticas defendidas no guia de investimento, produzido no Mato Grosso do Sul.

Passa-se então aos dados gerais, apresentando o país como exportador de commodities, como soja e carne, como de energia hidrelétrica, assinalando a forte 
dependência da economia em relação ao clima. Assim, uma seca prolongada, como a que se abateu sobre a região neste ano (H2FOZ, 2019), pode ser desastrosa para a economia.

A seguir, passa-se a mostrar a divisão territorial do país vizinho, num mapa bem colorido, e apresentam-se os dados populacionais. Tal construção do texto tem como objetivo inserir a informação de que os investimentos brasileiros neste território estão concentrados nas duas regiões mais populosas, Asunción e Ciudad del Este, e que as atividades são intensivas em mão de obra, nos setores de confecção, plásticos e calçados.

Mais duas vantagens econômicas são apresentadas ao leitor, o fato de o FMI informar que considera a dívida pública do Paraguai moderada, com "baixa inflação e balanças externas sólidas, além de uma política monetária bem equilibrada", é uma frase que pode vir a chamar a atenção dos potenciais investidores. Neste ponto o texto apela para o uso de uma autoridade para dar mais crédito às suas declarações, é o chamado argumentum ad verecundiam ${ }^{5}$ ou apelo à autoridade, apelando para o fato de o FMI ser uma fonte aparentemente confiável de informações econômicas.

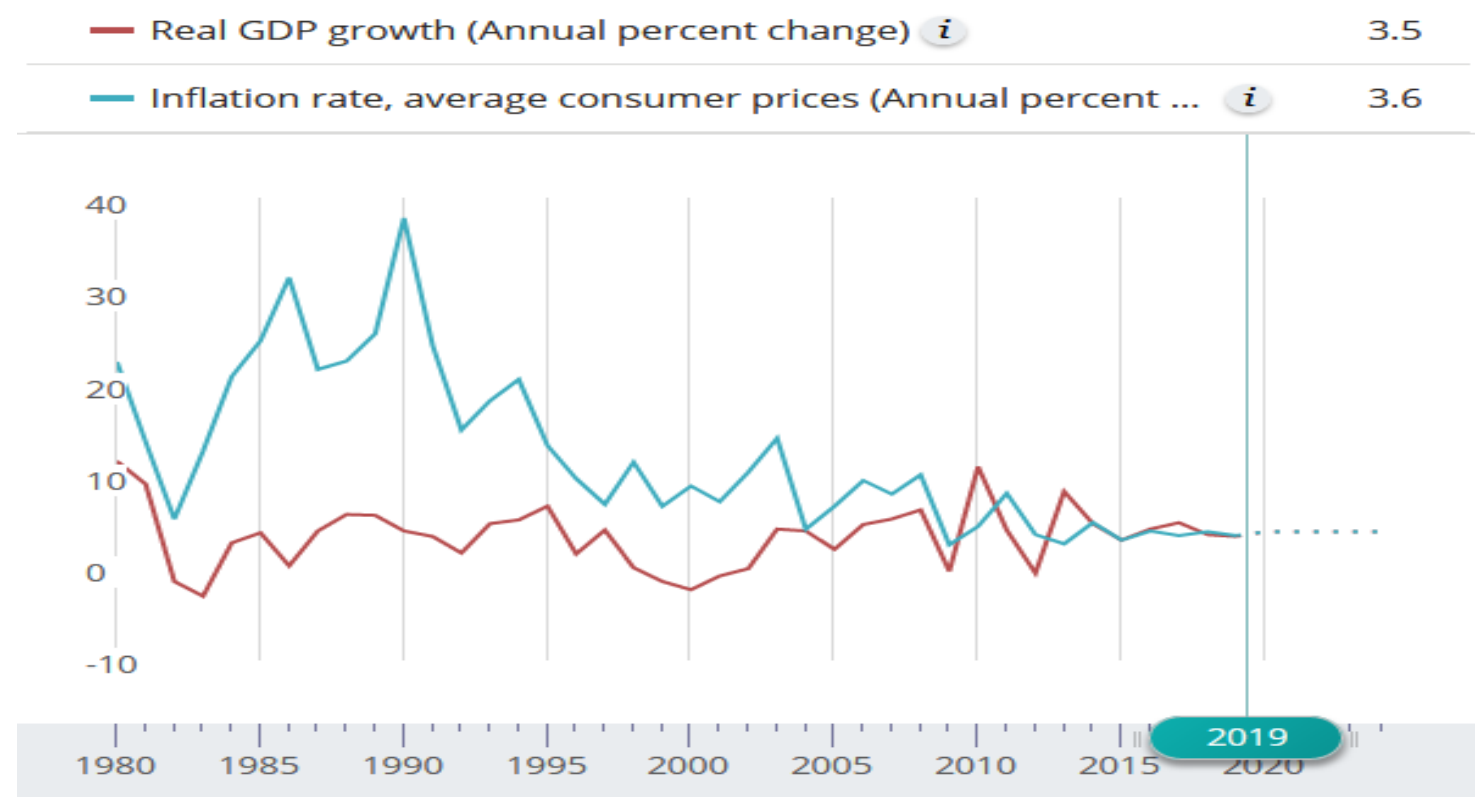

Relação entre inflação e crescimento do PIB.

\footnotetext{
${ }^{5}$ Consiste na utilização de uma autoridade reconhecida para dar legitimidade a nossos argumentos. Ver mais em: www.jstor.org/stable/40237194

Programas de Pós-Graduação em Ciências Sociais e Filosofia - UNIOESTE - Rua da Faculdade 645. Toledo - PR. CEP 85.903-000 Email: revistaalamedas@gmail.com
} 
Fonte: FMI. <https://www.imf.org/en/Countries/PRY>

O gráfico acima mostra a evolução da economia paraguaia utilizando-se de duas variáveis bem importantes, o índice de inflação e o índice de crescimento econômico. Se acompanharmos as linhas do gráfico iremos notar que a década de 1990 foi particularmente ruim para a economia do país, e que há uma melhora por volta de 2003, coincidindo com aumento do preço das commodities no mundo todo.

\section{Gráfico 1: Índice de commodities spot e futuro $(1967=100)$}

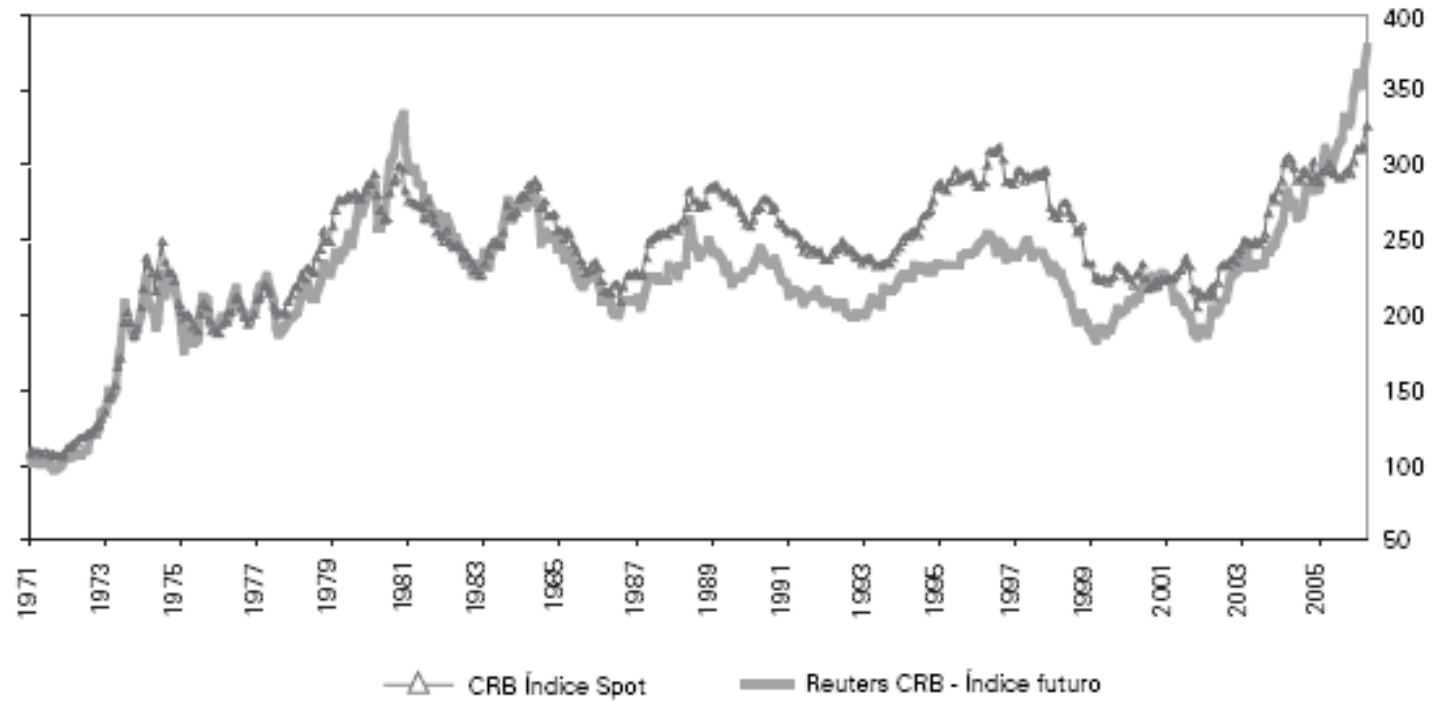

Fonte: PRATES, 2007.

Aqui o autor faz uma ressalva, e informa ao leitor que há alguns pontos problemáticos no Paraguai, que precisam ser melhorados, como o fato de ainda ser uma das economias mais pobres da região, de ter que melhorar a infraestrutura de hidrovias, rodovias e linhas de energia elétrica, de haver dependência do setor agrícola e de depender de vizinhos para escoar sua produção, ter problemas no governo, com corrupção e nepotismo, insegurança por parte do tráfico de drogas e da enorme informalidade e contrabando nas suas fronteiras.

A seguir o texto traz informações em formato de tabelas, uma com dados estatísticos do país, outra comparando taxas de inflação, desemprego, competitividade, com o Brasil. Outra com o PIB bruto e percentual de crescimento. E mais outra 
apresentando a competitividade comparando parâmetros econômicos do Brasil e do Paraguai, como demora para abertura de empresas, alvará de construção, obtenção de eletricidade, registro de propriedade, obtenção de crédito, etc.

A página 10 vai direto ao ponto com a questão: "Por que investir no Paraguai?", e as respostas vêm logo a seguir: maximizar a rentabilidade do patrimônio e capital; reduzir os custos operacionais; fugir da carga tributária brasileira; fugir dos encargos trabalhistas brasileiros; diversificar os riscos; internacionalizar a cadeia produtiva; penetrar em novos mercados.

Os verbos utilizados no trecho citado são bem característicos do tipo de propaganda, e reforçam ações bem contundentes: maximizar, fugir (duas vezes), diversificar e penetrar. Muita ação e o texto continua dando as dicas de como fazer tudo isso, numa explicação bem mastigada, aparentemente tentando dar ao investidor confiança, e lançando luz nos métodos de se concretizar tais ações.

Quadro 01- Comparativo Impostos Paraguai x Países MERCOSUL

\begin{tabular}{|l|l|l|l|l|}
\hline & PY & AR & UR & BR \\
\hline $\begin{array}{l}\text { IMPOSTO DE RENDA } \\
\text { PESSOA JURÍDICA }\end{array}$ & $<=10 \%$ & $35 \%$ & $25 \%$ & $34 \%$ \\
\hline $\begin{array}{l}\text { IMPOSTO DE RENDA } \\
\text { PESSOA FÍSICA }\end{array}$ & $10 \%$ & $35 \%$ & $25 \%$ & $27,5 \%$ \\
\hline $\begin{array}{l}\text { IMPOSTO SOBRE O VALOR } \\
\text { AGREGADO (IVA) }\end{array}$ & $<=10 \%$ & $21 \%$ & $23 \%$ & $25 \%$ \\
\hline
\end{tabular}

Quadro 01. Elaboraçã̃o CIN-MS- FIEMS, 2015. Fonte: REDIEX.

O quadro acima, reproduzido do guia de investimento, traz dados comparativos de impostos entre países do Mercosul, e demonstra as vantagens que se tem no Paraguai em função das cobranças bem menores neste quesito. $\mathrm{O}$ mesmo site do governo paraguaio, o Rediex, que serviu de fonte para a tabela acima é outro local de difusão de 
informações relevantes para investimentos no país, e produz um outro guia, chamado de "Guía Paraguay Exporta" que compila uma enorme quantidade de contatos de empresas produtoras, revendedoras e de serviços, voltadas para a exportação.

Mais à frente o guia faz referências a três diferenciais entre a economia paraguaia e a brasileira, com o intuito de realçar ainda mais as vantagens comparativas entre os dois países. O primeiro diferencial seria o custo da energia elétrica, que estaria 63,6\% menor do outro lado da fronteira; o segundo diferencial trata da mão de obra, onde $73 \%$ dos habitantes teriam menos de 34 anos, que no vizinho haveria o menor custo neste item dentre os países do Mercosul, e que teria um salário mínimo compatível ao nosso, mas que teve um aumento muito menor nos últimos anos, sendo de $67 \%$ no Paraguai e de $203 \%$ no Brasil, com mão de obra custando em média 20,7\% menos que no Brasil. Já o terceiro diferencial estaria no custo do solo, que ainda é menor que no Brasil, e que varia de acordo com a localidade e a facilidade de acesso.

Agora o texto passa a informar ao leitor a respeito dos incentivos ao investimento estrangeiro, começando por citar a Lei de Maquila, que é um regime de atração de investimentos para a implantação de empresas, ou subcontratação de outras existentes, processando e exportando bens, aumentando seu valor agregado. Tudo feito, mesmo a importação de insumos, com impostos suspensos, incidindo apenas as tarifas portuárias e de despachantes.

Não há impedimento quanto à constituição da empresa, desde que ela obedeça a um dos critérios definidos na lei de maquila: maquila pura, maquila por capacidade ociosa, submaquila, maquila de serviço intangível e maquila com programa albergue ou shelter. O Cemap (Cámara de empresas maquiladoras del Paraguay), como outros grupos afins, traz um grande número de informações, inclusive em português, explicando e incentivando a prática deste investimento.

Deve haver no mínimo a participação de $40 \%$ de "elemento paraguaio" para se enquadrar na lei de maquilas:

É considerado elemento paraguaio: A soma dos bens adquiridos para cumprir o contrato de maquila e submaquila (podendo ser bens adquiridos localmente ou importados em forma definitiva pelo maquilador ou sub-maquilador), mais os serviços contratados (incluem serviços de energia elétrica, água, 
telefone, ou outros similares; serviços de profissionais independentes; custos do financiamento de capital operacional da fábrica; seguro da planta industrial, matéria prima e produtos acabados; depreciação das máquinas caso seja de propriedade da maquiladora; aluguel ou locação pagos pela propriedade, plantas e equipamentos; outros serviços contratados não listados acima), além dos salários pagos incluindo os encargos sociais (FIEMS, p. 13).

Partindo-se destes dados parte-se para a lista de benefícios deste sistema: isenção de toda e qualquer taxa ou imposto sobre importação de insumos, suprimentos e bens de capital, fabricação e exportação, e mesmo IVA (imposto sobre o valor agregado), desde que dentro da lei. Caso paguem IVA pode-se recuperar o valor na forma de créditos fiscais, endossáveis e negociáveis (o que cria um outro mercado de créditos). Neste sistema de maquilas os impostos são temporariamente suspensos.

Além da lei de maquilas, o Paraguai oferece as facilidades da lei 60/90, que estabelece incentivos fiscais para investimentos de capital nacionais ou estrangeiros, pretendendo: aumentar a produção de bens e serviços; criar postos de trabalho; exportar e substituir importações; incorporar tecnologias. Para tal a lei garante isenção do IVA na compra de bens de capital locais ou importados, utilizados na indústria ou na agropecuária. Isenta, também, de todos os tributos da constituição e registro das empresas, assim como taxas e impostos sobre remessas ao exterior, ou pagamentos de financiamento estrangeiro (desde que mais de cinco milhões de dólares, em dez anos).

Mais um atrativo aos investimentos são as Zonas Francas, havendo duas no Paraguai, a Global e a Internacional, ambas localizadas em Ciudad del Este. O intuito é o de facilitar a logística das empresas e o de obter mais incentivos fiscais, desta vez provenientes da lei 523/95. Assim, a introdução de bens nas zonas francas acima está isenta de impostos nacionais, departamentais e municipais, incidindo apenas as taxas de serviços. Estas zonas francas são administradas por concessão num prazo de trinta anos.

Além destas zonas francas no Paraguai, há outras duas no território brasileiro, um no porto de Santos-SP e outro no porto de Paranaguá-PR. Ainda há mais duas na Argentina, em Buenos Aires e Rosário, duas no Chile, em Antofagasta e Iquique, e mais duas no Uruguai, e Montevidéu e Nueva Palmira. Tal estrutura amplia o alcance das possibilidades de receber investimentos por parte do Paraguai. 
Há, também, a lei 4427/12 que incentiva a montagem ou produção de bens de alta tecnologia, dando isenções nas tarifas de importação de insumos e de matériasprimas. Pode ser que esta lei esteja por traz do crescimento na oferta de marcas de produtos eletrônicos ofertados à venda nas lojas de Ciudad del Este, e que só são encontradas no Paraguai, assim como a venda dos receptores de Tv por assinatura e Iptv.

O texto do guia de investimento nos traz mais um dado interessante, a saber, a contrapartida brasileira ao incentivo de investimentos no país vizinho, que no caso é materializado pelo decreto estadual, do estado de Mato Grosso do Sul, No 14090 de 27/11/2014, que institui o Programa Fomentar Fronteiras. Tal programa beneficia importadores de produtos industrializados do Paraguai com o diferimento do ICMS (imposto sobre circulação de mercadorias e serviços), desde que instaladas nos municípios de fronteira entre o Mato Grosso do Sul e o Paraguai. Há um segundo benefício previsto em lei, o crédito presumido de $70 \%$ do ICMS das empresas contempladas pelo decreto.

A seguir o autor passa a descrever o processo de abertura de empresa no Paraguai, que consiste em: migração; abertura; registro; e abrir conta bancária. A migração consiste na radicação permanente do investidor no país vizinho, o que garante um registro de investidor a este diretor de empresa. Já a abertura e registro da empresa, seguindo-se o procedimento legal, leva por volta de 35 dias, e se assemelha aos procedimentos brasileiros, só que mais ágeis. O texto passa a descrever os tipos de empresa que podem ser abertas, dando dicas úteis aos pretendentes.

O próximo trecho versa a respeito da entrada no Paraguai, do regime de imigração, indo de residente permanente, a residente temporário, podendo ser não residente ou residente provisório. Segue então às dicas para ajudar no processo. Prazos e custo são descritos, como os locais onde comparecer e os tipos de comprovantes apresentar. Tudo bem descrito, como num bom manual.

Daí, passa-se aos aspectos trabalhistas mais relevantes, como: salário, formas de pagamento, direitos, tipos de contrato, período de experiência, estabilidade, destrato, demissão, jornada de trabalho, férias, licenças, décimo terceiro salário, salário família, 
sindicatos, disputas judiciais, previdência, etc. Abaixo a tabela apresenta o comparativo das práticas trabalhistas do país vizinho e as nossas.

Direitos trabalhistas: Brasil x Paraguai

\begin{tabular}{|c|c|c|}
\hline & BRASIL & PARAGUAI \\
\hline $\begin{array}{l}\text { FÉRIAS ANUAIS } \\
\text { REMUNERADAS }\end{array}$ & 30 DIAS & $\begin{array}{l}12 \text { DIAS PARA } 5 \text { ANOS } \\
\text { TRABALHADOS, } 18 \text { DIAS } \\
\text { PARA ATÉ } 10 \text { ANOS } \\
\text { TRABALHADOS, } 30 \text { DIAS } \\
\text { ACIMA DE } 10 \text { ANOS } \\
\text { TRABALHADOS. }\end{array}$ \\
\hline ESTABILIDADE & NÄO HÁ & $\begin{array}{l}\text { ESTABILIDADE APÓS } 10 \\
\text { ANOS CONSECUTIVOS } \\
\text { DE SERVIÇOS } \\
\text { PRESTADOS. } \\
\end{array}$ \\
\hline FGTS & $\begin{array}{l}8 \% \text { SOBRE AS } \\
\text { REMUNERAÇÕES E 50\% } \\
\text { DE MULTA RESCISÓRIA. }\end{array}$ & NÃO HÁ. \\
\hline CONTRIBUIÇÃO SINDICAL & $\begin{array}{l}0,02 \% \text { À } 0,8 \% \text { A.A SOB } \\
\text { O CAPITAL SOCIAL DA } \\
\text { EMPRESA. }\end{array}$ & NÃO HÁ. \\
\hline $\begin{array}{l}\text { CONTRIBUIÇÕES } \\
\text { PREVIDENCIÁRIAS }\end{array}$ & $\begin{array}{l}20 \% \text { A } 23 \% \text { SOBRE } \\
\text { AS REMUNERAÇŐES } \\
\text { PAGAS. }\end{array}$ & $\begin{array}{l}\text { 25,5\% SOBRE TODAS AS } \\
\text { REMUNERAÇÕES PAGAS. }\end{array}$ \\
\hline SISTEMA S & $\begin{array}{l}\text { 5,8\% SOBRE TODAS } \\
\text { AS REMUNERAÇÕES } \\
\text { PAGAS. }\end{array}$ & NÃO HÁ. \\
\hline
\end{tabular}

Tabela 06. Elaboração CIN-MS- FIEMS, 2015.Fonte: Presentacion País- FIESP.

Continuando com as dicas práticas para dar suporte aos possíveis investidores, que venham a se interessar em ler este guia, discute-se os aspectos ambientais, trâmites para obtenção de licenças, o registro de produtos, transportes, o registro de rótulos, registro de marcas, de patentes, como exportar e importar, sistema tarifário, chegando às dicas úteis ao cotidiano: de como chegar (carro, avião, etc.), quais feiras visitar, fuso horário, clima, corrente elétrica, moeda, cartões, bancos, segurança, saúde, vacinas, e uma lista de telefones úteis. 
O texto encerra com um conjunto de estatísticas, numa última tentativa de convencer o leitor de que o investimento no Paraguai é uma boa alternativa para aumentar os ganhos de capital provenientes de produção industrial ou prestação de serviços diversos, importando e exportando com incentivos inexistentes no Brasil, que como vimos, ou posterga o pagamento de impostos ou dá um certo desconto, mas nunca os suspende ou isenta.

\section{CONCLUSÃO}

Chegamos ao encerramento deste trabalho, que tentou demonstrar, com o uso de um material publicitário criado pela FIEMS, um exemplo de estratégia de influência no meio empresarial de maneiras de se aumentar o lucro do capital acumulado no nosso país, utilizando-se dos incentivos de renúncia fiscais praticadas pelo governo paraguaio, objetivando o aumento dos investimentos estrangeiros naquele país.

Como ganho neste processo obtivemos mais conhecimentos a respeito dos dados gerais sobre o Paraguai, sobre sua economia, suas vantagens comparativas em relação ao nosso país, conhecemos as leis de incentivo ao investimento, como a lei de maquilas - muito citada, mas pouco compreendida -, como outras leis no do território além da fronteira, como também um decreto no Mato Grosso do Sul (que citaremos adiante), e vimos os modos de se abrir uma empresa, de se nacionalizar, aspectos trabalhistas, ambientais, burocráticos, e as dicas pitorescas.

O início do texto demonstra que o autor tem consciência do desconhecimento generalizado de como são os países de nosso continente, pois tem que descrever a posição do Paraguai e colocar no mapa as localizações, demonstrando o nível de inconsciência nacional, mesmo entre os empresários, a respeito do mundo que nos cerca.

Mais abaixo o texto informa a presença de uma enorme quantidade de brasileiros no país, novamente tenta tapar um buraco no conhecimento do mundo por parte de nossos compatriotas, e tranquilizar o investidor de que ele será bem recebido. Tanto que a fonte de parte do texto provém da embaixada paraguaia no Brasil, ou seja, os 
discursos são semelhantes entre o governo vizinho e a federação industrial que produziu o guia.

Passa-se, assim, a apresentar o que realmente interessa, a economia do Paraguai, em termos do que se produz lá, e quais as vantagens que se pode obter fazendo o mesmo. Chega-se a citar dados do FMI assegurando a estabilidade econômica da nação vizinha. Mesmo assim, o autor faz ressalvas quanto a problemas de infraestrutura.

O convencimento parte de uma questão: "Por que investir no Paraguai?" E a resposta veio logo abaixo: maximizar, reduzir, fugir, diversificar, internacionalizar, penetrar. Todas estas ações de interesse do empresariado em qualquer lugar do mundo, mostrando que o texto foi feito de empresário para empresário, utilizando-se de sua linguagem própria, buscando atingir a um objetivo focal, o investimento.

Todo o tempo o objetivo é comparar as duas economias, mostrando as vantagens que tem do outro lado da fronteira. E se para o morador comum da fronteira tem-se como adágio "viver na fronteira é também viver da fronteira" (COLOGNESE, 2014, p. 72), para o empresariado brasileiro passar a fronteira é lucrar com a fronteira. Imaginemos o que não conseguiria um empresário, do mesmo setor de um outro no Brasil, ao produzir no Paraguai com as condições que as leis locais lhe oferecem.

Já a lei de maquilas, a lei 60/90, a lei 4427/12, as zonas francas, são um convite sedutor a qualquer um que tenha que arcar com os custos de se empreender no Brasil. Isto torna o empresário brasileiro no Paraguai um privilegiado, pois já começa a corrida pelo mercado com quilômetros à frente.

E, no Brasil, há um entrelaçamento das leis paraguaias com as leis estaduais do Mato Grosso do Sul, pois além das vantagens do outro lado da fronteira o decreto 14090/14 articula com aquelas e beneficia ainda mais o empresário com vantagens de prazo e descontos no ICMS. Isto demonstra como o capital ignora fronteiras e induz os governos a seguirem seus interesses, indo contra a lógica, apoiando investimentos no território vizinho em detrimento da sua própria população.

Mas, como diriam os romanos, “cui bono?”, quem se beneficia com todo este emaranhado de possibilidades de ganhos? Qual é a vantagem do Paraguai em abrir mão de receitas provenientes de impostos federais, departamentais e municipais, não 
privilegiando sua população, seus empresários, mas sim os habitantes do outro lado da fronteira?

As informações são poucas, no momento, para se ter certeza, mas a aparência é de que se esperava utilizar do exemplo chinês, que com estratégias semelhantes atraiu investimentos americanos, europeus e japoneses, que buscavam mão de obra barata, infraestrutura disponível e incentivos fiscais. $\mathrm{Na}$ china deu certo, pois houve aumento da produção, do crescimento do PIB, e o enriquecimento de parte da população.

Mas, no Paraguai pode ter se cometido um erro, pois suas condições estão longe de ser idênticas às chinesas de décadas atrás. Pois tem-se salários próximos aos praticados no Brasil; não há um governo centralizador e garantidor dos acordos firmados, como o do PC chinês; há a concorrência dos demais países que já seguiram este curso, e outros que já estão no meio do caminho, coisa que para a china não foi problema; o mercado chinês conta com um bilhão quatrocentos e cinco milhões de habitantes ${ }^{6}$, já o Paraguai tem pouco mais de sete milhões ${ }^{7}$, o que não ajudaria muito; o Brasil tem limites para investir, os americanos, europeus e japoneses não tinham a décadas atrás; a china investiu em educação, formando levas de profissionais especializados, o Paraguai ainda tem que apresentar tais especialistas.

Outro fato que não nos saiu da mente durante o trabalho, foi o de que, com todas estas facilidades - sem impostos, sem taxas, sem burocracia, com baixos custos, podendo importar e exportar com facilidade, podendo abrir facilmente uma empresa, podendo se tornar residente de várias maneiras - a chance de haver lavagem de capitais ilícitos por parte de particulares e de grupos criminosos é enorme. Tendo cuidado e discrição pode-se investir fortunas e sair de lá com o dinheiro limpo, pronto para justificar uma vida luxuosa.

Acreditamos que conseguimos apresentar a contento o guia em questão, querendo analisar o texto, a forma de comunicação empresarial, na tentativa de convencimento publicitário, com o intuito de promover o lucro industrial e comercial de grupos econômicos nacionais às custas das expectativas paraguaias de crescimento econômico.

\footnotetext{
${ }^{6} \mathrm{https}: / /$ countrymeters.info/pt/China.

${ }^{7}$ https://countrymeters.info/pt/Paraguay.

Programas de Pós-Graduação em Ciências Sociais e Filosofia - UNIOESTE - Rua da

Faculdade 645. Toledo - PR. CEP 85.903-000 Email: revistaalamedas@gmail.com
} 
Assim, cremos que nosso objetivo foi alcançado, lançando luz neste nebuloso mundo das leis de incentivo, aumentando nosso conhecimento a respeito das mesmas, chamando a atenção para o jogo do capital empresarial, que desconhece fronteiras quando o assunto é lucro, e as reforça quando o assunto é competição com o mercado internacional, pedindo benefícios e impondo barreiras.

Reconhecemos que o tema é árido, que não é algo tão interessante para se tratar, mas não sabemos, no exercício da pesquisa científica, quando um texto, um trabalho como este, pode vir a ser útil para um outro colega. O certo é que aprendemos muito com esta atividade, e muito pode ser descoberto, mesmo nos campos mais desprovidos de graça, tal como este.

Cremos que em um próximo trabalho alguém possa avançar na análise, procurar saber dos resultados práticos de tais medidas governamentais de incentivo. Houve melhoria das condições da população Paraguaia por conta de tais medidas? Houve transferência de tecnologia? Houve irregularidades praticadas por grupos criminosos? Qual a opinião da população de nosso vizinho com relação a tais benefícios?

\section{BIBLIOGRAFIA}

CÁMARA DE COMERCIO PARAGUAY BRASIL. Guia de Inversiones 2018-2019. Disponível em: <https://issuu.com/camaradecomercioparaguaybrasil/docs/gui_a_de_inv ersiones_2018_-_2019_-_>. Acesso em: 01 de ago. 2019.

CEMAP. Ley de Maquila: una alternativa de desenvolvimiento regional. Disponível em: 〈http://www.maquila.org.py/?p=2551>. Acesso em 01 de ago. 2019.

CIN-MS-FIEMS. Guia de Investimento Paraguai, 2015. Disponível em: <www.fiems. com.br/public/confederacoes/guia_de_investimento_paraguai.pdf>. Acesso em: $29 \mathrm{de}$ julho 2019.

COLOGNESE, Silvio Antônio; CARDIN, Eric Gustavo. As Ciências Sociais nas Fronteiras: Teorias e Metodologias de Pesquisa. Cascavel: JB, 2014.

FMI. Fundo Monetário Internacional. Disponível em: < http://www.imf.org>. Acesso em: 01 de ago. 2019.

FOLHA DIGITAL. Com crescimento acima da média, Paraguai vira caso de sucesso na região. Disponível em: 
$<$ https://www1.folha.uol.com.br/mercado/2017/02/1855944-com-crescimento-acimada-media-paraguai-vira-caso-de-sucesso-na-regiao.shtml>. Acesso em: 01 de ago. 2019.

H2FOZ. PIB paraguaio deve despencar dos $4 \%$ previstos para apenas $1,9 \%$ este ano. Disponível em: <https://www.h2foz.com.br/noticia/pib-paraguaio-deve-despencardos-4-previstos-para-apenas-19-este-ano>. Acesso em: 01 de ago. 2019.

MATO GROSSO DO SUL. Decreto No 14090, de 27 de novembro de 2014. Programa Fomentar Fronteiras. Disponível em: <https://www.legisweb.com.br/legislacao/?id= 277913>. Acesso em: 01 de ago. 2019.

PARAGUAI. Ley No 1.064, de 13 de maio de 1997. De la Industria Maquiladora de Exportacion. Disponível em: <https://www.aduana.gov.py/uploads/archivos/LEY\%20N _\%201064.pdf>. Acesso em: 01 de ago. 2019.

Ley $\mathrm{N}^{\circ}$ 60, de 31 de março de 1990. Régimen de Incentivos Fiscales para la Inversión de Capital de Origen Nacional y Extranjero. Disponível em: $<$ http://www.im puestospy.com/Leyes/Ley\%2060_90.php>. Acesso em: 01 de ago. 2019.

. Ley $\mathrm{N}^{\circ}$ 523, de 24 de novembro de 1995. Ley que Autoriza y Establece el Regimen de Zonas Francas. Disponível em: <http://www.mcs.com.py/Leyes/4\%20Ley \%20523-94\%20De\%20Zonas\%20Francas.pdf>. Acesso em: 01 de ago. 2019.

Ley $\mathrm{N}^{\circ}$ 4427, de 15 de março de 2012. Ley que Establece Incentivos para la Producción, Desarrollo o Ensamblaje de Bienes de Alta Tecnología. Disponível em: <http://www.bacn.gov.py/leyes-paraguayas/1269/ley-n-4427-estableceincentivos-para-la -produccion-desarrollo-o-ensamblaje-de-bienes-de-alta-tecnologia>. Acesso em: $01 \mathrm{de}$ ago. 2019.

PRATES, Daniela Magalhães. A alta recente dos preços das commodities. Rev. Econ. Polit., São Paulo, v. 27, n. 3, p. 323-344, Sept. 2007. Disponível em: $<$ http://www.scielo.br/scielo.php?script=sci_arttext\&pid=S0101-31572007000300001\& lng=en\&nrm=iso >. Acesso em: 01 de ago. 2019.

REDIEX. Guía Paragauy Exporta. Disponível em: <http://www.rediex.gov.py/>. Acesso em: 01 de ago. 2019.

WOODS, John;WALTON , Douglas. "Argumentum Ad Verecundiam." Philosophy \&Rhetoric, vol. 7, no. 3, 1974, p. 135-153. JSTOR. Disponível em: <www.jstor.org/stable/40237194>. Acesso em: 16 de set. 2019. 